\title{
Analysis of Crisis Phenomena in the Russian Economy Using Fast Indicators of Economic Security
}

\author{
S. N. Mityakov ${ }^{a, *}$ and E. S. Mityakov ${ }^{b}$ \\ ${ }^{a}$ Alekseev State Technical University, Nizhny Novgorod, Nizhny Novgorod, 603950 Russia \\ ${ }^{b}$ MIREA Russian Technological University, Moscow, 199454 Russia \\ *e-mail:snmit@mail.ru
}

Received November 24, 2020; revised December 22, 2020; accepted January 12, 2021

\begin{abstract}
This article shows the possibility of applying short-term (fast) indicators of economic security to analyze crisis phenomena in the economy of Russia. The system includes the indicators adopted in the Strategy for the Economic Security of the Russian Federation up to 2030. It is proposed to jointly analyze these indicators through new nonlinear normalizing functions that contain their threshold and target values as parameters. The fast indicators system is used to analyze four economic crises in Russia, including their prerequisites and the pace and depth of the recession and subsequent recovery of the real economy and other sectors, such as the financial and social sectors, and foreign trade. Integral indices are synthesized for these sectors, the composite index of economic security is calculated, and the patterns of their joint movement are considered. The RTS index is singled out among the forward-looking indices that can be potential forerunners of a crisis.
\end{abstract}

Keywords: economic crises, short-term indicators of economic security, average and composite indices, comparative analysis, crisis forerunners

DOI: $10.1134 / \mathrm{S} 1075700721030096$

Introduction. The system of Russia's economic security indicators proposed in the Institute of Economics of the Russian Academy of Sciences (IE RAS) includes 36 variables divided into four subsets, that is, the financial sector, the real economy, foreign trade, and the social sector $[1,2]$. In addition to the indicators proper, the system includes threshold levels, which, when they were not reached, indicated a violation of the stability of the economic system. The subsequent studies, instead of rigid threshold values, many authors began to use so-called risk zones, drawn up depending on the remoteness of an indicator from its threshold [3]. Economic security indicators have a one-year sampling period, which allows studying midterm and long-term economic trends and can be used in strategic planning and forecasting documents.

At the same time, it should be noted that the origination and development of crisis phenomena in the economy are often more rapid and usually take several weeks or months. This is why the formation of realtime economic forecasts and the timely analysis of economic situations require using so called short-term (fast) indicators, updated in a one-month sampling period. These indicators are used in [4] for making the comparative analysis of the 1998-1999 and 20082009 crises in Russia's economy. In [5], where crisis phenomena in Russia's economy are analyzed, the period for analysis is extended from January 1996 to
March 2015. Compared with [4, 5], this study uses an even larger time range for analysis and an expanded set of indicators according to the Strategy for the Economic Security of the Russian Federation up to 2030 adopted in 2017 and referred to hereafter as the Strategy.

Methodology of monitoring economic security by means of fast indicators. The system of 12 fast indicators of Russia's economic security is presented in Table 1. They are grouped in four areas of economic security. Most of these indicators are included in the current list of indicators defined in the Strategy. According to the draft regulation proposed by the Ministry of Economic Development of Russia, a special certificate has been made up for each of the certificates from the Strategy. In addition, the target and the maximum admissible (critical) value of each indicator have been determined [6]. These values as well as the used sources of information are presented in Table 1.

The choice of indicators has been conditioned by the availability of an official information source, the possibility of using them for operational analysis, the absence of mutual dependence, and the relevance to economic security management. For example, the analysis did not cover such indicators, as the fixed asset depreciation rate, poverty rate, as well as several other indicators measured each year and used for strategic analysis. The monetary aggregate had a fairly 
Table 1. Short-term (fast) indicators of economic security

\begin{tabular}{|c|c|c|c|c|}
\hline No. & Indicator name & Target value & Critical value & Taken from \\
\hline \multicolumn{5}{|c|}{ Real economy } \\
\hline 1. & Physical GDP index, $\%$ & 4 & 1.5 & http://www.gks.ru \\
\hline 2. & Industrial production index, $\%$ & 6.5 & 0 & http://www.gks.ru \\
\hline 3. & Fixed capital expenditure index, $\%$ & 5 & 0 & http://www.gks.ru \\
\hline \multicolumn{5}{|c|}{ Social sector } \\
\hline 4. & Labor market strain index (unemployed/vacancy ratio) & 1 & 3 & http://www.gks.ru \\
\hline 5. & Actual expendable money income index, $\%$ & 4 & 0 & http://www.gks.ru \\
\hline 6. & Retail turnover index, $\%$ & 3.5 & 0 & http://www.gks.ru \\
\hline \multicolumn{5}{|c|}{ Financial and monetary sector } \\
\hline 7. & $\begin{array}{l}\text { Coverage of monthly imports of goods and services with gold } \\
\text { and foreign exchange reserves, months }\end{array}$ & 22 & 3 & http://www.cbr.ru \\
\hline 8. & Annual inflation rate, $\%$ & 4 & 13 & http://www.gks.ru \\
\hline 9. & Net capital exports, $\%$ of exported goods and services & 0 & 25 & http://www.cbr.ru \\
\hline \multicolumn{5}{|c|}{ Foreign trade } \\
\hline 10. & Foreign debt, $\%$ of GDP & 30 & 50 & http://www.cbr.ru \\
\hline 11. & Physical exports index, $\%$ & 6 & 2 & http://www.gks.ru \\
\hline 12. & Physical imports index, $\%$ & 6 & 2 & http://www.gks.ru \\
\hline
\end{tabular}

Table 2. Stock market and additional indicators

\begin{tabular}{|c|c|c|}
\hline Variable no. & Indicator name & Taken from \\
\hline & & Stock indicators \\
\hline 1. & Oil price, USD/barrel & http://protown.ru \\
\hline 2. & Dow Jones index & http://kurs-kotirovka.ru/birzhevyie-indeksyi \\
\hline 3. & RTS index & http://www.rts.ru \\
\hline 4. & USD/RUB exchange rate & $\begin{array}{l}\text { http://www.kurs-dollara.ru } \\
\text { Additional indicators }\end{array}$ \\
\hline 5. & T-bill return index & http://www.cbr.ru \\
\hline 6. & Case-Shiller index & http://us.spindices.com/indices \\
\hline 7. & Sanctional pressure index & http://www.wansors.com \\
\hline 8. & Government response index & $\begin{array}{l}\text { https://evercare.ru/index.php/news/v-oksforde-zapuschena-sistema- } \\
\text { otslezhivaniya-reagirovaniya-pravitelstv-raznykh-stran-na-covid }\end{array}$ \\
\hline
\end{tabular}

strong correlation with the consumer price index, which was why it was not considered as well. The internal debt indicator has not only been below the threshold level for many years but also approximated the target value. Thus it was not analyzed due to irrelevance. At the same time, two extra variables close to those considered in the Strategy were added. For example, the fixed capital expenditure index was used instead of the explicitly seasonal ratio of fixed asset investments to GDP. The actual expendable income index was used instead of the poverty rate determined as the percent of the country's citizens with income below subsistence level.

In addition to the main indicators (Table 1), the analysis also covered a group of stock market and additional indicators (Table 2). These groups were considered as exogenous (external) parameters of the model. The stock market indicators chosen were the oil price,
RTS index, USD/RUB exchange rate, and the Dow Jones index. The additional indicators that forerun crises will be considered below.

The factor of seasonality was excluded by linear filtration (moving mean method). If the sampling period exceeded a month, linear interpolation was used but if that period was shorter, averaging methods were used.

To make their joint analysis possible, the indicators were reduced to dimensionless form and common limits of possible variations [7]. In this case, the so-called traffic light model with three risk zones was used [8]. According to Table 1, the indicators with subcritical values were included in the red zone, the ones with values between target and critical were included in the yellow zone, and those with values above target were included in the green zone. Table 1 contains both, direct and reverse indicators. The growth of the former, for example, the physical GDP index, has a positive effect on the 
Table 3. Normalizing functions

\begin{tabular}{l|c|c}
\hline \multicolumn{1}{c}{ Function name } & Direct indicator formula $(a<b)$ & Reverse indicator formula $(a>b)$ \\
\hline Sigmoid & $y=\frac{3}{1+\exp \left(\frac{b+a-2 x}{b-a} \ln 2\right)}$ \\
Arctangensoida & $y=\frac{3}{\pi}\left(\frac{\pi}{2}+\arctan \left(\left(\tan \frac{\pi}{6} \frac{2}{b-a}\right)\left(x-\frac{a+b}{2}\right)\right)\right)$ \\
Logarithmoid & $g=\frac{\ln x+\ln b-2 \ln a}{\ln b-\ln a} ; y=g, 0 \leq g \leq 3 ; y=0, g<0 ; y=3, g>3 ; a>0 ; b>0 ; x>0$ \\
\hline
\end{tabular}

national economy. On the contrary, the growth of the latter, for example, the annual inflation rate, downgrades the economic security level.

One of the three nonlinear functions from Table 3 is proposed for a normalizing function. The specific kind of function is chosen depending on the range of potential indicator changes, the size of the yellow zone, and other factors.

In Table 3, $x$ is the original indicator, $y$ is the transformed indicator, $a$ is the critical value, and $b$ is the target value. After the calculation by one of the formulas from Table 3, all of the variables are transformed to direct; in this case, the critical and the target values are shown at levels $y=1$ and $y=2$, whereas the tolerance region of the transformed indicators includes section $\mathrm{y} \in[0,3]$.

To make an aggregate analysis of the situation by various economic security projections, integral indices were synthesized [9] as

$$
S_{i}=W Y_{i}^{T},
$$

where $Y_{i}=\left\langle y_{1}, y_{2}, \ldots, y_{m}\right\rangle_{i}$ is the row matrix of values of the indicators of the $i$ th sphere, $W=\left\langle w_{1}, w_{2}, \ldots, w_{m}\right\rangle$ is the vector of weight coefficients, and $\sum_{j=1}^{m} w_{j}=1, m$ is the number of a projection's variables.

Then, the composite index of economic security is calculated as

$$
\Psi=\Omega S^{T},
$$

where $S=\left\langle S_{1}, S_{2}, \ldots, S_{l}\right\rangle$ is the row matrix of integral indices of economic security projections, $\Omega=\left\langle\omega_{1}, \omega_{2}, \ldots, \omega_{l}\right\rangle$ is the vector of weight coefficients of economic security projections, and $\sum_{i=1}^{l} \omega_{i}=1$, where $l$ is the number of projections.

Like normalized indicators, indices have a tolerance range from zero to three in which case an index value of one is some general threshold and an index value of two is a general target level.

The linear normalizing functions making it possible to show the values of the indicators along one axis in a range of $[0,100]$ were used for the stock market and extra indicators.
Analyzing the evolution of the 1998-1999 economic crisis. The evolution dynamics of this crisis are shown in Fig. 1. In the plots of this figure the variations in the integral indices of economic security (derived for four projections), stock market indices, and T-Bill return index are shown. The growth of the T-Bill returns was essentially the direct cause of the crisis. In the words of A. R. Belousov, "Since 1995, we simply had no opportunity other than maintaining the system of reproduction by a large-scale raising of capital. In 1996, that was the raising of capital from the public. In 1997, when the inclination for saving money weakened, we had to raise nonresident funds. The degree of imbalance in the system of reproduction made it unsustainable. The only options we had were either to ensure an increase in production that would make the production sector close to the consumption sector, or topple the consumption sector..." [10, p. 55]. The national government chose the second option by devaluating the currency and declaring a default.

As shown by analyzing the movement in the indices, the initial point for the development of the crisis was a downswing in the actual expendable household income in August and September 1997. That was attended almost simultaneously by a downward change in the RTS index and global oil prices. The real economy sector suffered from a significant downward change in the physical GDP index and the IPI in the context of extremely low fixed capital expenditures. In the social sector the downward change in household income was attended by increased strains in the labor market, followed by a deterioration in consumer demand and retail turnover. In the financial and monetary sector, a major advance in prices in July and September 1998 attended the turbulent outflow of capital and the coverage of imports with currency and gold reserves in critical amounts. The foreign trade sector responded by a major drop in IMEX operations and a growth of foreign debt that recovered to its precrisis value for three years. The financial sector suffered most of all because its recovery took more than three years.

Thus, with certain external prerequisites, the crisis had been largely conditioned by domestic processes, which was confirmed by the absence of downward change in the Dow Jones index. 
(a)

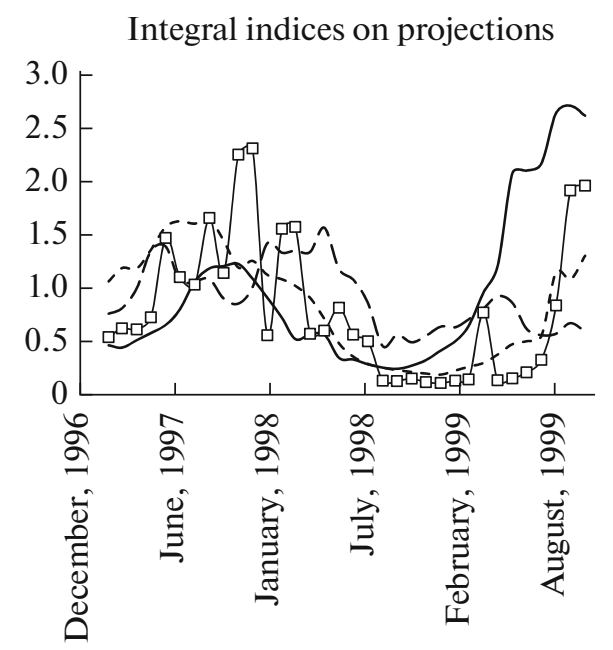

(b)

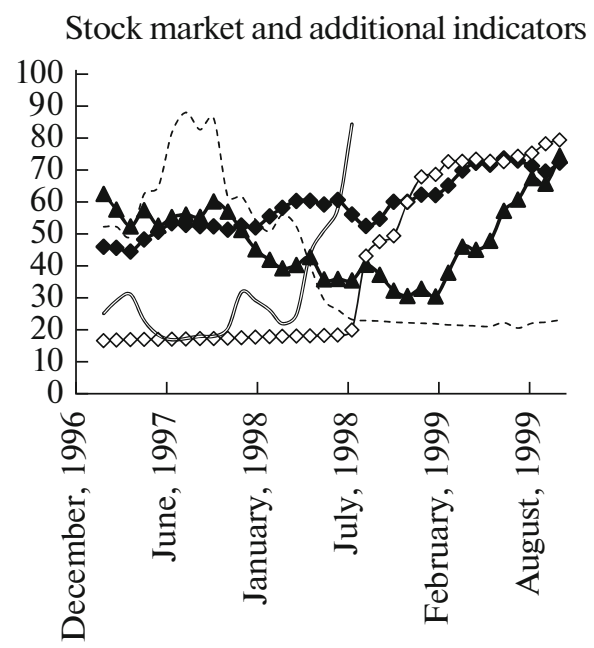

Fig. 1. Evolution of the 1998-1999 crisis:

(a) the straight line shows the situation in the real economy;

the short and long dashes show the respective variations in social sector and the financial and monetary sector; the rectangle with dashes on both sides shows the situation in foreign trade;

(b) the narrow rectangle with dashes on both sides shows the variations in oil prices;

the rhombus with dashes on both sides shows the variations in the Dow Jones index;

the short dashes show the variations in the RTS index;

the dot in bold with dashes on both sides shows the variations in the USD-RUB exchange rate;

the rectangle with dashes on both sides shows the variation in the T-Bill return index.

Analyzing the evolution of the 2008-2009 economic crisis. The evolution of this global crisis is shown in Fig. 2. The crisis was caused by mistakes in the mortgage credit lending in the United States, which is seen from the variations in the Case-Shiller index that indicates the housing prices in the 20 largest cities of the United States.

The 2008-2009 global crisis heavily affected the processes in Russia's economy. According to B. N. Porfiriev [11], Russia was vulnerable to that crisis for two reasons. The first of them is the extractive focus and low diversification of its economy; the second reason is the delay in and low efficiency of the anticrisis steps taken by the national government at different levels of administration.

As seen from Fig. 2, there were no significant changes in the composite financial sector index on average. The real sector suffered a more significant decline than in 1998 and recovered in one year and a half. There was also a major decline in the foreign trade index due to the downward changes in IMEX operations. The index recovered to its precrisis levels by March 2010. The social sector responded to the crisis by turbulent changes in actual expendable household income, an increase in labor market strains, and a downswing in the retail turnover index. This index recovered to its precrisis value only by July 2010 .
Analyzing the evolution of the 2014-2016 economic crisis in Russia. The movement in the fast indicators of economic security that reflects the evolution of the 2014-2016 crisis is shown in Fig. 3.

The prerequisites for the crisis were congestive economic tendencies, administrative malfunctions, high criminalization levels, an excessively liberalized and extractive national economy, and other phenomena. The situation was aggravated by the sanctions imposed on Russia in the spring of 2014 and the decline in energy prices that began in June 2014. In this analysis, the sanctional pressure index pro rata with the number of US-based companies that have imposed sanctions on Russia since 2014 is used as an extra indicator. The initial phase of the crisis was attended by a drop in the RTS index against a smooth movement in the Dow Jones index, a decline in energy prices, and an advance in the USD/RUB exchange rate.

Figure 3 shows that the downward movements in the composite security indices in the real economy, social, and financial and monetary sectors were not so significant as in the foreign trade sector. The particularity of this crisis is not the degree of decline in individual indicators but a steady long-time recession turning to stagnation. The values of the IPI and the fixed capital expenditure index remained supercritical for almost three years. The situation in the social sector exhibited low strains in the labor market but a downward change in the actual expendable household 
(a)

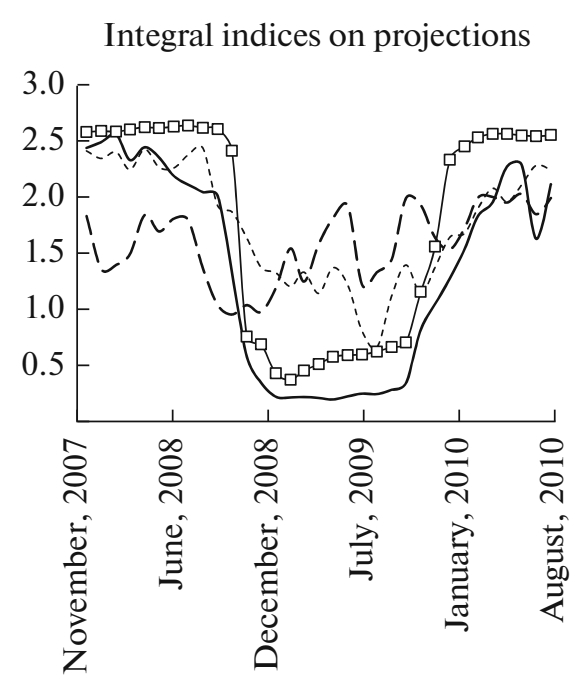

(b)

Stock market and additional indicators

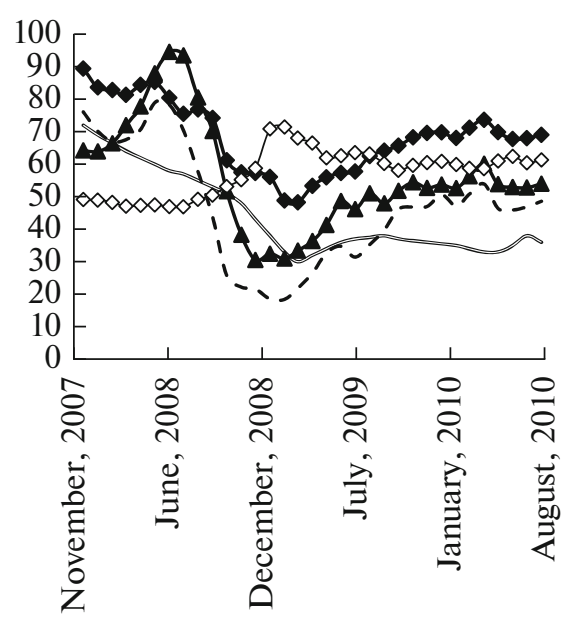

Fig. 2. Evolution of the 2008-2009 crisis:

(a) the straight line shows the situation in the real economy; the short and long dashes show the respective variations in social sector and the financial and monetary sector;

the rectangle with dashes on both sides shows the situation in foreign trade;

(b) the narrow rectangle with dashes on both sides shows the variations in the oil price;

the rhombus with dashes on both sides shows the variations in the Dow Jones index;

the short dashes show the variations in the RTS index;

the dot in bold with dashes on both sides shows the variations in the USD-RUB exchange rate;

the dashes of various length show the variations in the Case-Shiller index.

(a)

Integral indices on projections

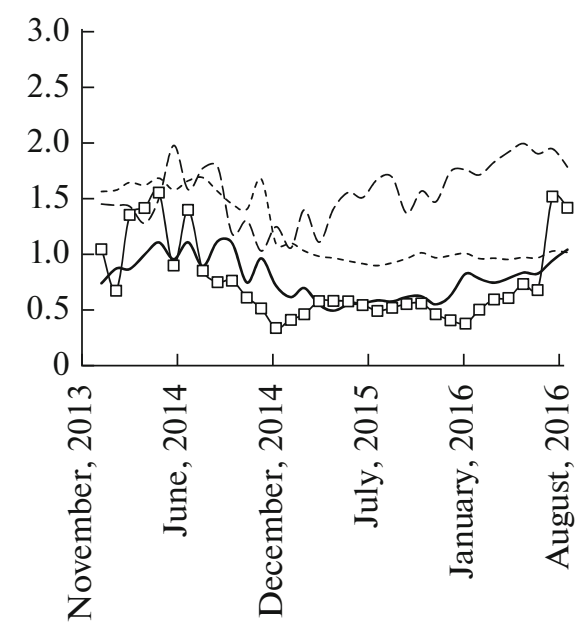

(b)

Stock market and additional indicators

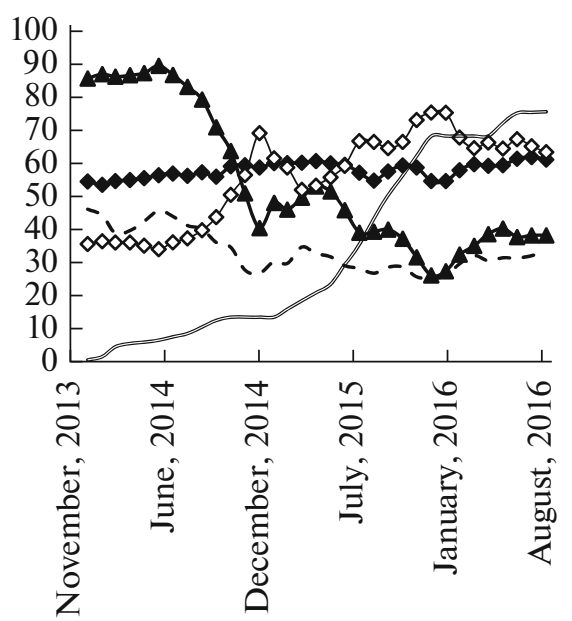

Fig. 3. Evolution of the 2014-2016 crisis:

(a) the straight line shows the situation in the real economy; the short and long dashes show the respective variations in social sector and the financial and monetary sector;

the rectangle with dashes on both sides shows the situation in foreign trade;

(b) the narrow rectangle with dashes on both sides shows the variations in oil prices;

the rhombus with dashes on both sides shows the variations in the Dow Jones index;

the short dashes show the variations in the RTS index;

the dot in bold with dashes on both sides shows the variations in the USD-RUB exchange rate;

the dashes of various length show the sanctional pressure index. 
(a)

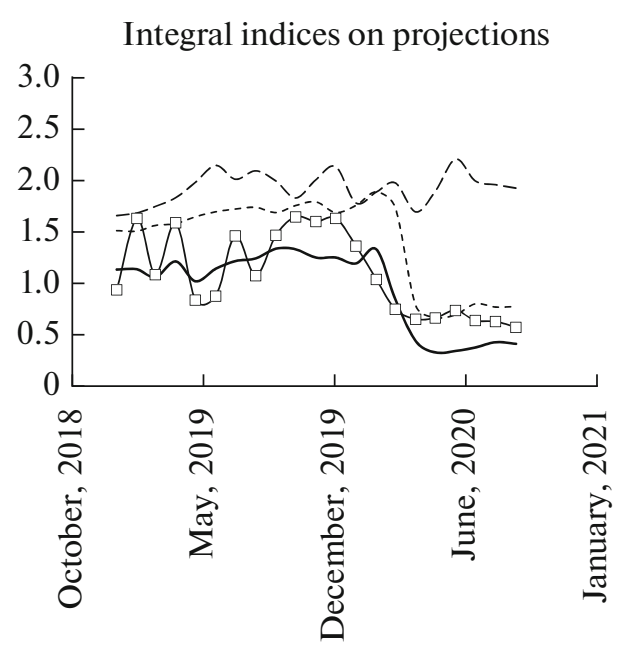

(b)

Stock market and additional indicators

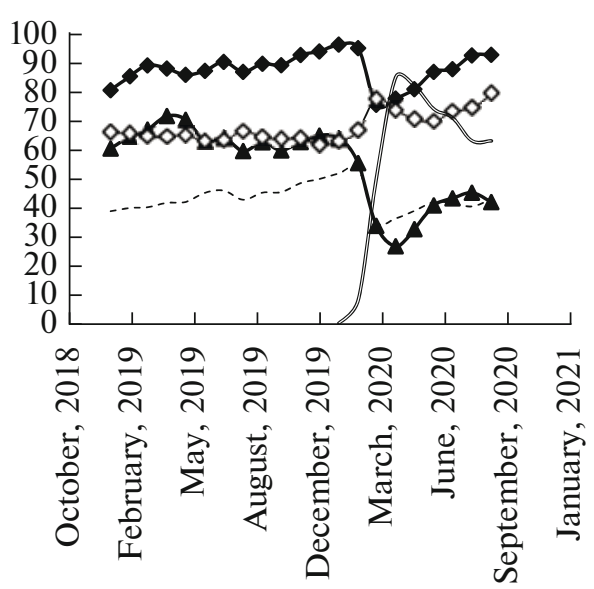

Fig. 4. Evolution of the 2020 crisis

(a) the straight line shows the situation in the real economy; the short and long dashes show the respective variations in the social sector and the financial and monetary sector;

the rectangle with dashes on both sides shows the situation in foreign trade;

(b) the narrow rectangle with dashes on both sides shows the variations in oil prices;

the rhombus with dashes on both sides shows the variations in the Dow Jones index;

the short dashes show the variations in the RTS index; the dot in bold with dashes on both sides shows the variations in the USD-RUB exchange rate;

the dashes of various length show the government response index.

income and a downswing in the retail turnover index in January 2015. An insignificant and short-term advance in inflation was attended by a downward change in the outflow of capital and high levels of currency and gold reserves. On the whole, the financial sector suffered to a lesser degree. The foreign trade sector exhibited a drastic and extended decline in physical exports and imports indices. That said, imports and exports recovered to their precrisis levels only by July and November 2016, respectively.

Analyzing the evolution of the 2020 economic crisis. In the opinion of A.A. Shirov, the current crisis is not market-determined but has to do with the decision of the governmental authorities to put on hold the activity in several branches of the economy [12]. From our point of view, the evolution of the crisis in Russia is conditioned by a combination of two factors. The first of them is the coronavirus pandemic, and the second is the downward change in oil prices due to the abrogation of the arrangements made as part of the OPEC+ group deal. These two factors went off almost simultaneously and caused a downward change in most of the indicators of economic security. Russia's economy has been in the phase of recession since 2012 . This is probably why the decline in the economic variables was not so significant as in several developed economies.

As seen from Fig. 4, unlike in other crises, in this case the decline in the indicators was almost simulta- neous. The movement in the stock market and additional indicators exhibited an almost simultaneous slump in oil prices and the RTS and Dow Jones indices, and also an advance in the USD/RUB exchange rate that remained high for a long period. The government response index that shows the level of counterpandemic measures (travel restrictions, shutdown of enterprises and organizations, fiscal and monetary methods) began to go up two months before the real development of the pandemic in Russia. This is due to the fact that the country's top-level leaders wanted to set the national healthcare system in the state of full readiness. The financial sector was the only one of all the four economic security projections that remained almost undamaged.

It should be noted that in this crisis the social sector has sharply plummeted for the first time since the 1998-1999 crisis; furthermore, the decline was registered for all of the three indicators. The normalized index of actual expendable household income went down from 1.28 in February to 0.68 in March; the labor market strain coefficient went down from 2.16 in March to 1.84 in April and 1.31 in August; and the retail turnover index dropped from 2.37 in March to 0.12 in April.

As shown by analyzing the movement in the variables of Russia's economy from January to October 2020 [13], the greatest decline was exhibited by the indices of retail turnover, exports, imports, and, par- 


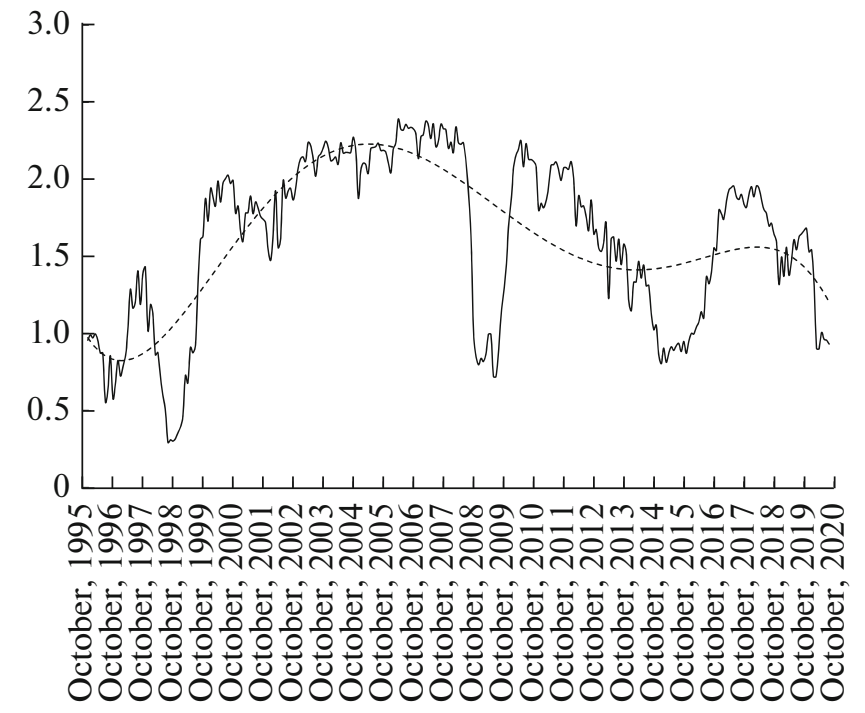

Period

Fig. 5. Variations in the composite index of Russia's economic security from January 1996 up to September 2020.

ticularly, commercial services to the public. Most of them recovered to their precrisis values by October. At the same time, it will be possible to make judgments about the degree and duration of the current crisis only after its end.

It should also be noted that this crisis leads to a significant decline in the country's demographic rates. On the one hand, the downward change in income results in the downward change in the birth rates; on the other hand, there is a major increase in the death rates. Thus, in October 2020 the average national death rate was by $30 \%$ higher than in October 2019 and nearly one half of the increment had nothing to do with COVID-19 [13].

Analyzing the movement in the composite index of economic security. The movement in this index is shown in Fig. 5. The analysis of this figure reveals a nonlinear trend indicative of unstable movements in the indicators of economic security. This trend is a good background for highlighting the negative momenta that correspond to the four economic crises described above.

In Fig. 5, it is clearly seen that from January 2002 to August 2008 and from March 2010 to March 2012 the index steadily grew and exceeded the value of two that corresponded to the tentative benchmark. When the national economy went through the periods of development and crisis (from January to April 1996, from April 1997 to August 1999, from December 2008 to September 2009, from January 2015 to March 2016, from April to September 2020), the composite index was below one. In the remaining periods its value floated between one and two. The increased frequency of economic crises, the latter of which is of essential importance, gives cause for some concerns. On the whole, the set of composite indices can be a good strategic planning and forecasting tool.

Analytical comparison of the crises. The spider plot with normalized fast indicators of economic security for the four considered crises is shown in Fig. 6. The lowest points of decline of the national economy shown in the plot date back to January 1999, July 2009, June 2015, and May 2020.

It is seen from the evolution of these crises that the most problem-plagued indices are the retail turnover index, the physical exports and imports index, the

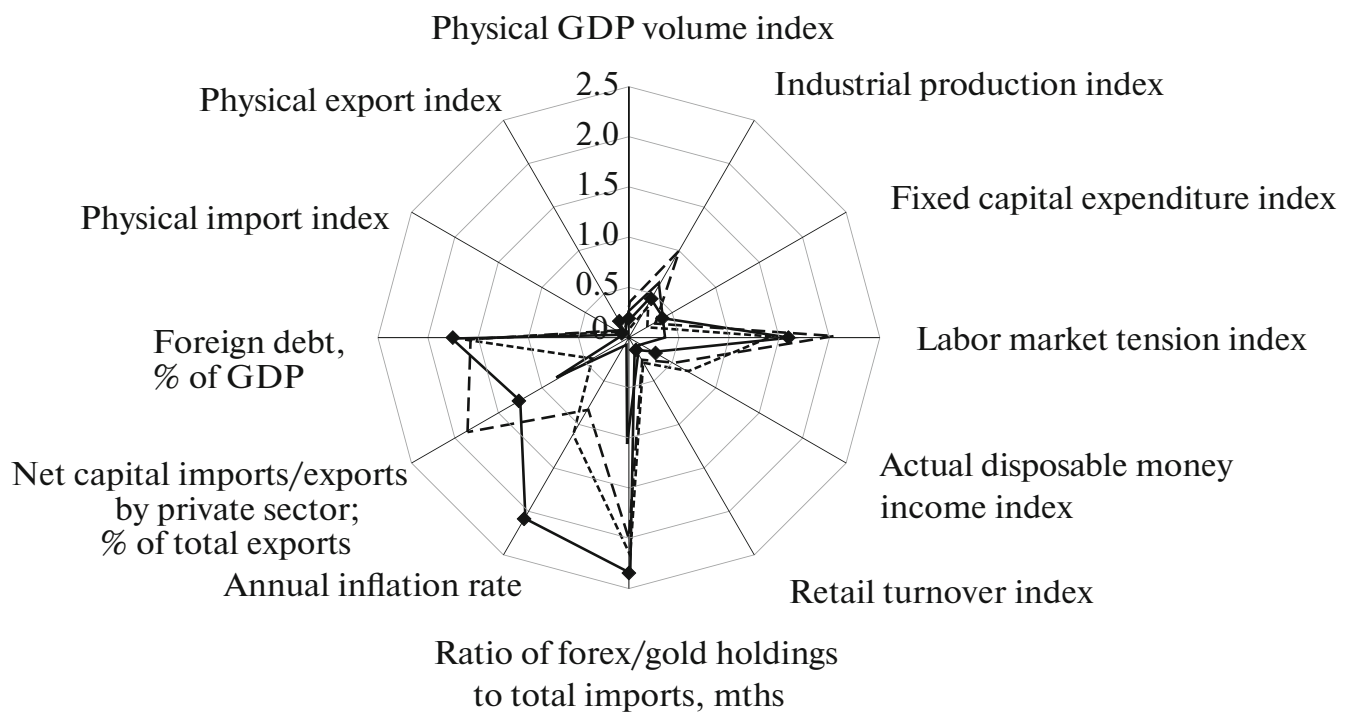

Fig. 6. The indicators of the four economic crises compared on the spider plot: the straight line, the dotted line, the short dashes, and the rhombus with dashes on both sides show the situation in January 1999, July 2009, June 2015, and May 2020, respectively. 
Table 4. Change in the values of the indicators in the course of economic crises

\begin{tabular}{|c|c|c|c|c|c|}
\hline \multirow{2}{*}{ No. } & \multirow{2}{*}{ Indicator name } & \multicolumn{4}{|c|}{ Crisis } \\
\hline & & I & II & III & IV \\
\hline 1. & Physical GDP index & $l v 1 s c$ & $l v 1 s c$ & $a v 4 w c$ & $a v 0 s c$ \\
\hline 2. & Industrial production index & $l v 3 s c$ & $a v 1 s c$ & $a v$ & $l v 0 s c$ \\
\hline 3. & Fixed capital expenditure index & $s v$ & $l v 2 s c$ & $a v 3 w c$ & $a v 0 s c$ \\
\hline 4. & Labor market strain index & $s v$ & $l v 5 w c$ & $l v$ & $l v 2 a c$ \\
\hline 5. & Actual expendable money income index & $l v-1 s c$ & chs & $a v 3 w c$ & $a v 0 a c$ \\
\hline 6. & Retail turnover index & $l v 5 s c$ & $l v 5 s c$ & $l v 5 s c$ & $l v 1 s c$ \\
\hline 7. & $\begin{array}{l}\text { Coverage of monthly imports of goods and services with gold } \\
\text { and foreign exchange reserves }\end{array}$ & $a v$ & $l v$ & $l v$ & $l v$ \\
\hline 8. & Annual inflation rate & $l v 9 s c$ & $a v$ & $l v 5 a c$ & $l s v$ \\
\hline 9. & Net capital exports, $\%$ of exported goods and services & $c h$ & $c h$ & $a v 2 s c$ & $c h$ \\
\hline 10. & Foreign debt, $\%$ of GDP & $a v 3 a c$ & $a v 2 w c$ & $a v 4 a c$ & $l v 4 l c$ \\
\hline 11. & Physical exports index & $\operatorname{ch} 5 s c$ & $l v 2 s c$ & sv $3 a c$ & $s v-1 a c$ \\
\hline 12. & Physical imports index & $\operatorname{ch} 5 s c$ & $l v 2 s c$ & sv $3 a c$ & $l v-2 s c$ \\
\hline 13. & Oil price, USD/barrel & $s v 1 l c$ & $l v 1 s c$ & $l v 1 a c$ & $a v 0 s c$ \\
\hline 14. & Dow Jones index & $a v$ & $1 a c$ & $a v$ & $0 a c$ \\
\hline 15. & RTS index & Oct. 97 & Sept. 08 & Aug. 14 & Mar. 20 \\
\hline 16. & USD/RUB exchange rate & $11 s c$ & $3 a c$ & $3 a c$ & $0 a c$ \\
\hline 17. & Business confidence index & - & 2 & 4 & 2 \\
\hline
\end{tabular}

Notation: $s v$ is the small parameter value; $a v$ is the average parameter value; $l v$ is the large parameter value; $w c$ is the weak parameter change; $a c$ is the average parameter change; $s c$ is the strong parameter change; $c h$ is the chaotic parameter behavior. The number of months of delay in the beginning of the downward change in a respective index relative to the initial date of the changes in the RTS index is shown as a digit.

physical GDP index, and the fixed capital expenditure index. The crises have also had a major impact of varying degrees on the actual expendable monetary household income index and the industrial production index. In recent years the values of foreign debt, currency and gold reserves, labor market strains, and annual inflation rates have been close to target, which does prove that the country has significant reserves for countering crises. Having passed critical points in its movement, the outflow of capital exhibits a major spread in values, which means greater risks for the national economy.

According to work [14], a crisis is often forerun by the RTS index. For the data on the values of the indicators of economic security, the delay in the start of their decline relative to the start of the decline in the RTS index, and on the depth of this decline, see Table 4. As shown by analyzing Table 4 , in most of the cases the crises were forerun by the RTS index.

Conclusions Thus, the article presents a specially developed system of fast indicators of economic security and their threshold values for analyzing and forecasting emerging crisis situations to decide on providing fast responses at operational decision-making levels. The object of research is crisis situations in the economy (collapses in commodity and financial markets, epidemics, pandemics, natural calamities and catastro- phes with critical economic aftermath, social, criminal, terrorist tensions and dangers). The study can be applied in practice for making operational forecasts and control and decisions for public authorities. At the intercountry level these guidelines will encourage the sustainable development of BRICS, EurAsEC, CIS, and other such unions. At the country level they can be in demand at various public authority institutions, including the Administration of the President and the Government of Russia, and used in elaborating strategic documents for the socioeconomic development of this country. The use of the study findings at the level of federal subjects will allow their administrations to correctly evaluate the situation and make scientifically grounded decisions on the anticrisis management and control over the economic growth of the territories in the context of limited resources.

Together with the framework of variable-setting tools and the calculation of the integral and composite indices, the presented system of indicators will facilitate more adequate evaluation and forecasts of crisis phenomena in the economy. The subject matter can be further developed for expanding the developed set of tools with machine-learning techniques and artificial intelligence, which will allow switching over to an 
essentially new level of analyzing crisis phenomena in the economy.

\section{REFERENCES}

1. Modernization of the Financial Sphere of Russia: Monograph, Ed. by V. K. Senchagov (Nestor-Istoriya, St. Petersburg-Moscow, 2011) [in Russian].

2. The Strategy of Economic Security in the Development of Indicative Plans of Socio-Economic Development for the Long and Medium Term: Monograph, Ed. by V. K. Senchagov (Inst. Ekon. Ross. Akad. Nauk, Moscow, 2009) [in Russian].

3. E. S. Mityakov and S. N. Mityakov, "Assessment of risks in the problems of monitoring threats to economic security," Tr. Nizhegorod. Gos. Tekh. Univ. im. R. E. Alekseeva, No. 1, 44-51 (2018).

https://doi.org/10.46960/1816-210X_2018_1_44

4. V. K. Senchagov and S. N. Mityakov, "Comparative analysis of the impact of the financial and economic crises of 1998 and 2008-2009 on indicators of Russia's economic security,” Vestn. Finans. Univ., No. 6, 71-88 (2013).

5. V. K. Senchagov and S. N. Mityakov, "Evaluation of economic crises using short-term indexes and average indexes of economic security of Russia," Stud. Russ. Econ. Dev. 27, 148-158 (2016). https://doi.org/10.1134/S1075700716020131

6. "The Ministry of Economic Development determined macro-indicator values critical for the security of the Russian Federation," Interfax, Apr. 1 (2019). https:// www.interfax.ru/business/656619. November 9, 2020.
7. V. K. Senchagov and S. N. Mityakov, "Using the index method to assess the level of economic security," Vestn. Akad. Ekon. Bezop. MVD Ross., No. 5, 41-50 (2011).

8. Strategic Risks of Russia: Estimates and Forecast, Ed. by Yu. L. Vorob'eva (Delovoi Ekspress, Moscow, 2005) [in Russian].

9. E. S. Mityakov and S. N. Mityakov, "Comparative analysis of approaches to calculating the generalized index of Russia's economic security," Sovrem. Probl. Nauki Obraz., No. 3, 307 (2014).

10. A. R. Belousov, "Economic recession and structural imbalances in reproduction," Ekon. Nauka Sovrem. Ross., Suppl., 53-58 (1998).

11. B. N. Porfiriev, "Economic crisis: Management and innovative development issues," Stud. Russ. Econ. Dev. 21, 472-476 (2010).

12. A. A. Shirov, "Opportunities and risks of post-crisis economic recovery," Nauchn. Tr. Vol'nogo Ekon. O-va. Ross. 223 (3), 75-80 (2020). https://doi.org/10.38197/2072-2060-2020-223-3-75-80

13. S. N. Mityakov, "Effect of the corona crisis on the economic security of Russia," Razvit. Bezop., No. 4, 4-16 (2020). https://doi.org/10.46960/2713-2633_2020_4_4

14. S. N. Mityakov, "Monitoring as a tool for diagnosing economic crises," in Economic Security of Russia: Methods of Assessment and Control. Proc. III Int. Sci.-Pract. Conf. 'Senchagov Readings' (Inst. Ekon. Ross. Akad. Nauk, Moscow, 2019), pp. 206-216.

Translated by S. Kuznetsov 